\title{
Red Blood Cell Transfusions Following Resection of Skull Base Meningiomas: Risk Factors and Clinical Outcomes
}

\author{
Carlito Lagman ${ }^{1}$ John P. Sheppard ${ }^{1} \quad$ Joel S. Beckett ${ }^{1} \quad$ Alexander M. Tucker ${ }^{1} \quad$ Daniel T. Nagasawa $^{1}$ \\ Giyarpuram N. Prashant ${ }^{1}$ Alyssa Ziman ${ }^{2}$ Isaac Yang1,3,4,5,6,7
}

\footnotetext{
${ }^{1}$ Department of Neurosurgery, Ronald Reagan UCLA Medical Center, Los Angeles, California, United States

2 Wing-Kwai and Alice Lee-Tsing Chung Transfusion Service, Department of Pathology and Laboratory Medicine, David Geffen School of Medicine at UCLA, Los Angeles, California, United States

${ }^{3}$ Head and Neck Surgery, Ronald Reagan UCLA Medical Center, Los Angeles, California, United States

${ }^{4}$ Radiation Oncology, Ronald Reagan UCLA Medical Center, Los Angeles, California, United States

5 UCLA Jonsson Comprehensive Cancer Center, Ronald Reagan UCLA Medical Center, Los Angeles, California, United States

6 Department of Neurosurgery at Harbor UCLA Medical Center, Torrance, California, United States

${ }^{7}$ Los Angeles Biomedical Research Institute (LA BioMed) at Harbor UCLA Medical Center, Torrance, California, United States
}

J Neurol Surg B 2018;79:599-605.

\author{
Address for correspondence Isaac Yang, MD, 300 Stein Plaza, \\ Suite 562, Los Angeles, CA 90095-1761, United States \\ (e-mail: IYang@mednet.ucla.edu).
}

\begin{abstract}
Keywords

- blood transfusion

- meningioma

- surgery

- skull base

Objective This article identifies risk factors for and investigates clinical outcomes of postoperative red blood cell transfusion in patients with skull base meningiomas.

Design Retrospective cohort study.

Setting Single academic medical center.

Participants The transfusion group included patients who had skull base meningiomas and who received packed red blood cell (RBC) transfusion within 7 days of surgery. The no transfusion group included patients who had skull base meningiomas but who did not have RBCs transfused within 7 days of surgery.

Main Outcome Measures In-hospital complication rate, length of stay (LOS), and discharge disposition.

Results One hundred and ninety-six patients had a craniotomy for resection of a meningioma at our institution from March 2013 to January 2017. Seven patients had skull base meningiomas and received RBC transfusion within 7 days of surgery (the transfusion group). The skull base was an independent risk factor for transfusion after we controlled for the effect of meningioma size (OR 3.89, 95\% Cl 1.34, 11.25). Operative time greater than 10 hours was an independent risk factor for prolonged hospital stay (OR $8.84,95 \% \mathrm{Cl} 1.08,72.10$ ) once we controlled for the effect of transfusion. In contrast, transfusion did not independently impact LOS or discharge disposition once we controlled for the effect of operative time.
\end{abstract}

received

November 30, 2017

accepted after revision

March 31, 2018

published online

May 14, 2018 (c) 2018 Georg Thieme Verlag KC

Stuttgart . New York
DOI https://doi.org/

10.1055/s-0038-1651502.

ISSN 2193-6331. 
Conclusions The skull base is an independent predictor of RBC transfusion. However, RBC transfusion alone cannot predict LOS or discharge disposition in patients who undergo surgical resection of a skull base meningioma.

\section{Introduction}

Red blood cell (RBC) transfusion is used to raise the blood's oxygen-carrying capacity. The 2016 AABB guidelines (formerly the American Association of Blood Banks) considers transfusion appropriate at hemoglobin values of 7 to $8 \mathrm{~g} / \mathrm{dL}$ in a hemodynamically stable patient without active bleeding. ${ }^{1}$ Transfusion is generally not indicated at hemoglobin values between 8 and $10 \mathrm{~g} / \mathrm{dL}$, but may be appropriate in some settings including symptomatic anemia and ongoing bleeding. $^{2}$ Other transfusion guidelines are available for a wide range of clinical settings. ${ }^{3-8}$ However, guidelines for $\mathrm{RBC}$ transfusion in brain tumor patients have not yet been established, in part due to the paucity of available literature.

Currently, most studies focus on transfusions in subarachnoid hemorrhage, traumatic brain injury, and spine surgery. ${ }^{9}$ Risk factors for and clinical outcomes of RBC transfusion in skull base surgery have not been thoroughly investigated. Critical neurovascular structures enter the cranial vault at the level of the skull base and resection of even benign lesions such as meningiomas can be incredibly complex. Consequently, the risk of bleeding and postoperative anemia is higher. Addressing those complications is a principal concern of skull base surgeons.

Here, we present a retrospective review of patients who underwent resection of a skull base meningioma and compared patients who had RBCs transfused in the postoperative period to patients who did not have RBCs transfused in the postoperative period. The study objectives are to identify risk factors for and to investigate clinical outcomes of postoperative $\mathrm{RBC}$ transfusion in patients with skull base meningiomas.

\section{Patients and Methods}

\section{Study Design}

We retrospectively reviewed adult patients who had a craniotomy for resection of a meningioma at a single academic medical center over 4 years (March 2013-January 2017) and identified patients who had skull base meningiomas. The study population included patients who had nonrecurrent skull base meningiomas, antiplatelet therapy discontinued at least 7 days before surgery, a preoperative baseline hemoglobin value above $9 \mathrm{~g} / \mathrm{dL}$, and a normal international normalized ratio (INR).

We stratified patients into transfusion and no transfusion groups. The transfusion group included patients who had skull base meningiomas and who received RBC transfusion within 7 days of surgery. The no transfusion group included patients who had skull base meningiomas but who did not have RBCs transfused within 7 days of surgery. The institutional review board approved this study.

\section{Data Extraction}

We extracted demographic characteristics (age, sex, and race), medical histories, hemoglobin value, platelet counts, prothrombin time, INR, meningioma size, features of vessel encasement, preoperative embolization status, American Society of Anesthesiologist (ASA) class, operative time, Simpson grade, World Health Organization (WHO) grade, and days to transfusion from the electronic medical record. We did not extract estimated blood loss (EBL) from the preoperative note because this metric is underestimated. We also trended hemoglobin values through discharge in the transfusion group.

To investigate meningioma size as a biomarker for transfusion, we retrieved maximal diameters $(\mathrm{cm})$ from preoperative radiologic records. Our outcomes of interest included in-hospital complication rate, length of stay (LOS) in days, and discharge disposition. We defined a prolonged hospital stay as a total LOS equal to or greater than 14 days. We defined routine discharge as a discharge to home, and nonroutine discharge as a discharge other than to home.

\section{Statistical Analyses}

We performed univariate analyses to compare the transfusion and no-transfusion groups. We performed Pearson's and point biserial correlations for continuous and dichotomized dependent variables, respectively. We performed multivariate analyses using logistic regression and the Mantel-Haenszel method ${ }^{10}$ to evaluate potential risk factors for blood transfusion and the outcomes of interest.

We divided operative time and meningioma size into quartiles and then dichotomized those values to identify cutoff thresholds at which the risk of transfusion was significant. We defined statistical significance as a $p$-value of less than 0.05 . We performed statistical analyses using $R$ version 3.4.0 (University of Auckland, New Zealand) and SAS Studio (SAS Institute, Cary, North Carolina, United States).

\section{Results}

One hundred and ninety-six patients had a craniotomy for resection of a meningioma at our institution from March 2013 to January 2017. Seven patients had skull base meningiomas and had RBCs transfused within 7 days of surgery (the transfusion group). Patients who had skull base meningiomas were more frequently transfused with RBCs within 7 days of surgery ( $18.92 \%$ vs. $5.66 \%, p=0.02)$ and the skull base was an independent risk factor for transfusion after we controlled for the effect of meningioma size (odds ratio [OR], 3.89, 95\% confidence interval [CI], 1.34, 11.25).

The transfusion group was older (67.29 vs. 57.03 years, $p=0.03)$ and had larger tumors (5.64 vs. $3.44 \mathrm{~cm}$, 
$p<0.001$ ), longer operative times (10.52 vs. 7.19 hours, $p=0.002$ ), longer hospital stays (19.93 vs. 4.93 days, $p<0.001)$, and more nonroutine discharges $(71.43 \%$ vs. $10 \%, p<0.001)$ than the no transfusion group. Patient age $\left(R_{\mathrm{pb}}=0.35, \quad p=0.03\right)$, meningioma size $\left(R_{\mathrm{pb}}=0.56\right.$, $p<0.001$ ), and operative time positively correlated with transfusion $\left(R_{\mathrm{pb}}=0.48, p=0.002\right)$.

Univariable analyses ( - Table 1 ) showed that meningioma size greater than $5 \mathrm{~cm}$ was a risk factor for transfusion (OR $75,95 \%$ CI 5.80). Operative time greater than 10 hours was a risk factor for transfusion (OR 12.50, 95\% CI 1.87, 83.60), inhospital complications (OR 5.25, 95\% CI 1.11, 24.91), and nonroutine discharge (OR 8.00, 95\% CI 1.42, 44.92). Multivariable analyses (-Table 2 ) showed that operative time greater than 10 hours was an independent risk factor for prolonged hospital stay (OR 8.84, 95\% CI 1.08, 72.10) once we controlled for the effect of transfusion.

In contrast, transfusion did not independently impact LOS or discharge disposition once we controlled for the effect of operative time. - Table 3 summarizes the transfusion group and - Fig. 1 shows the trends in hemoglobin values for the transfusion group. A lower postoperative hemoglobin value was a risk factor for transfusion (OR 0.30, 95\% CI 0.11, 0.78). On average, the duration from surgery to transfusion was $2.10 \pm 1.61$ days. Fifty-seven percent of patients had RBCs transfused at hemoglobin values between 7 and $8 \mathrm{~g} / \mathrm{dL}$. Forty-three patients had RBCs transfused at hemoglobin values between 8 and $10 \mathrm{~g} / \mathrm{dL}$. On average, we transfused $1.86 \pm 0.69$ units and $520.71 \pm 193.98 \mathrm{~mL}$ of RBCs. We did not observe adverse transfusion reactions during any index hospitalization.

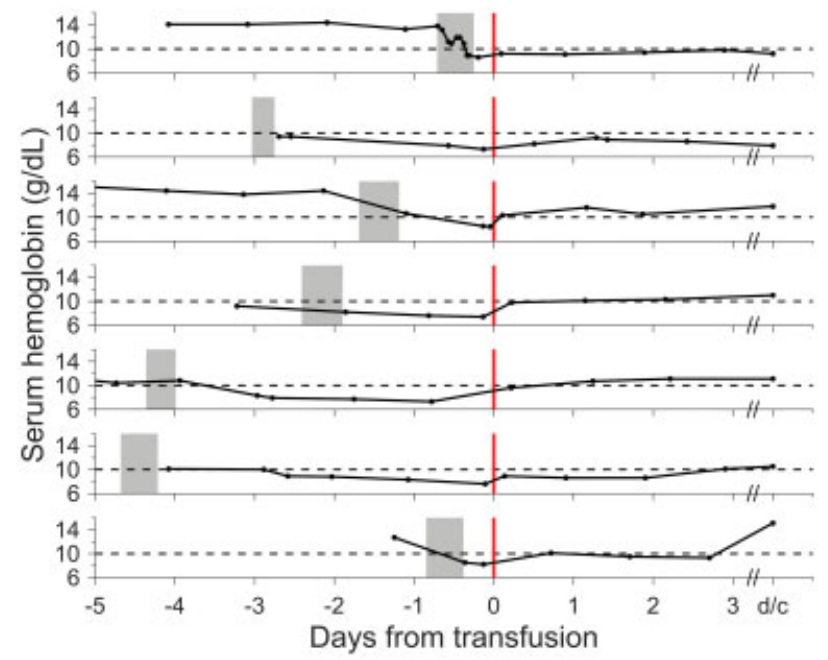

Fig. 1 Hemoglobin trends for patients in the transfusion group. The shaded box represents the surgical procedure (craniotomy for tumor resection) and the red line in the center of the figure represents the transfusion. Based on that information, we are able to see hemoglobin values at four time points: (1) preoperative, (2) postoperative, (3) pretransfusion, and (4) posttransfusion. All seven patients were transfused below a hemoglobin threshold of $10 \mathrm{~g} / \mathrm{dL}$ (dashed lines) and were stable at discharge (both hemodynamically and neurologically).

\section{Discussion}

Several studies in the neurosurgical literature have reported on the impact of blood transfusions on morbidity and mortality. We summarized these studies in a recent systematic review, which showed that most articles focused on subarachnoid hemorrhage and traumatic brain injury. ${ }^{9}$ Only four clinical studies investigated blood transfusions in brain tumor surgery and a single paper emphasized complex skull base surgery. ${ }^{11-14}$ Thus, the study herein described addresses a need in neurosurgical discourse.

This study examined clinical and radiographic risk factors for blood transfusion after resection of skull base meningiomas at one academic medical center over a period of 4 years (March 2013-January 2017). During the specified study period, a total of 875 patients underwent craniotomy for tumor resection. Of those 875 patients, 72 patients had at least 1 unit of RBCs transfused in the perioperative period. Our overall transfusion rate of $8.22 \%$ is consistent with the transfusion rate reported in a recent national database study. ${ }^{15}$

The skull base was an independent risk factor for transfusion. Skull base meningiomas are often highly vascular and can encase large vessels. At our institution, we readily use virtual reality to visualize the complex angioarchitecture of these tumors for the purposes of preoperative planning. ${ }^{16}$ Among skull base meningiomas, vessel encasement was more frequently reported in the transfusion group but had no significant effect on outcomes.

The transfusion group had larger tumors than the no transfusion group. We discovered that meningioma size greater than $5 \mathrm{~cm}$ was a risk factor for transfusion. However, the small sample size precluded multivariable analyses. Therefore, we were unable to determine if meningioma size greater than $5 \mathrm{~cm}$ was an independent risk factor for transfusion. To investigate meningioma size as a biomarker for transfusion, we retrieved maximal diameters from preoperative radiologic reports and ran correlation analyses to determine the relationship between size and RBC transfusion. Meningiomas size was not significantly correlated with units or volume transfused.

To further interrogate the concept of tumor size as a biomarker for transfusion, we measured meningioma volumes by way of semiautomated three-dimensional tumor volumetry in a post hoc analysis. We contoured the tumors by consensus on three standard planes using the image analysis software ITK-SNAP version 3.4 .0 (available at http://www. itksnap.org). ${ }^{17-19}$ Still, meningioma volume was not significantly correlated with units or volume transfused.

The transfusion group had longer operative times than the no transfusion group. In one of our cases (operative time of 11 hours), prolonged attempt at hemostasis amid the surgical bed caused us to order intraoperative complete blood count and coagulation parameters, which revealed a decrease in hemoglobin value from 13.30 to $8.60 \mathrm{~g} / \mathrm{dL}$ and platelet count from 158,000 to $98,000 / \mu \mathrm{L}$, and prothrombin time from 11.80 to 13.20 seconds. That patient had 1 unit of RBCs and 2 units of plasma transfused in the immediate postoperative period. That case highlights the need to balance the goal of achieving 
Table 1 Univariate analyses

\begin{tabular}{|c|c|c|c|c|}
\hline & All patients & Transfusion & No transfusion & $p$-value \\
\hline Baseline & $n=37$ & $n=7$ & $n=30$ & \\
\hline Age, y & $59.97 \pm 11.53$ & $67.29 \pm 7.06$ & $57.03 \pm 11.58$ & 0.03 \\
\hline Female, $n(\%)$ & $29(78.38)$ & $7(100)$ & $22(73.33)$ & 0.31 \\
\hline White race, $n(\%)$ & $18(48.64)$ & $1(14.29)$ & $17(56.67)$ & 0.09 \\
\hline Nonwhite race, $n(\%)$ & $19(51.35)$ & $6(85.71)$ & $13(43.33)$ & 0.09 \\
\hline Asian & $10(27.03)$ & $3(42.86)$ & $7(23.33)$ & \\
\hline Hispanic & $5(13.51)$ & $2(28.57)$ & $3(10)$ & \\
\hline Black & $2(5.41)$ & $0(0)$ & $2(6.67)$ & \\
\hline Other & $2(5.41)$ & $1(14.29)$ & $1(3.33)$ & \\
\hline \multicolumn{5}{|l|}{ Medical history, $n(\%)$} \\
\hline Liver disease & $1(2.70)$ & $1(14.29)$ & $0(0)$ & 0.19 \\
\hline Coagulopathy & $4(10)$ & $1(14.29)$ & $3(10)$ & 1 \\
\hline Antiplatelet & $10(27.03)$ & 1 (14.29) & $9(30)$ & 0.65 \\
\hline Anticoagulant & $8(21.62)$ & $2(28.57)$ & $6(20)$ & 0.63 \\
\hline Stroke & $3(8.11)$ & $1(14.29)$ & $2(6.67)$ & 0.48 \\
\hline Seizure & $5(13.51)$ & $1(14.29)$ & $4(13.33)$ & 1 \\
\hline \multicolumn{5}{|l|}{ Hemoglobin, g/dL } \\
\hline Preoperative & $12.84 \pm 1.82$ & $12.20 \pm 1.98$ & $13.08 \pm 1.70$ & 0.10 \\
\hline Postoperative & $11.09 \pm 1.66$ & $9.45 \pm 1.06$ & $11.48 \pm 1.55$ & 0.003 \\
\hline \multicolumn{5}{|l|}{ Platelet count, $10^{3} / \mu \mathrm{L}$} \\
\hline Preoperative & $232.27 \pm 75.45$ & $222.60 \pm 62.38$ & $234.50 \pm 78.95$ & 0.91 \\
\hline Postoperative & $207.94 \pm 71.45$ & $215.40 \pm 72.42$ & $176.9 \pm 62.50$ & 0.31 \\
\hline \multicolumn{5}{|l|}{ Meningioma } \\
\hline Size, cm & $3.89 \pm 1.56$ & $5.64 \pm 1.27$ & $3.44 \pm 1.30$ & $<0.001$ \\
\hline Vessel encasement, $n(\%)$ & $16(43.24)$ & $5(71.43)$ & $11(36.67)$ & 0.09 \\
\hline \multicolumn{5}{|l|}{ ASA class, $n(\%)$} \\
\hline$I-I I$ & $12(32.43)$ & $1(14.29)$ & $11(36.67)$ & \multirow[t]{2}{*}{0.40} \\
\hline III-IV & $25(67.57)$ & $6(85.71)$ & $19(63.33)$ & \\
\hline \multicolumn{5}{|l|}{ Management } \\
\hline Embolization, $n(\%)$ & $10(27.03)$ & $4(57.14)$ & $6(20)$ & 0.07 \\
\hline Operative time, $\mathrm{h}$ & $7.82 \pm 2.73$ & $10.52 \pm 1.83$ & $7.19 \pm 2.51$ & 0.002 \\
\hline \multicolumn{5}{|l|}{ Simpson grade, $n(\%)$} \\
\hline$|-I| I$ & $17(45.95)$ & $2(28.57)$ & $15(50)$ & \multirow[t]{2}{*}{0.42} \\
\hline IV-V & $20(54.05)$ & $5(71.43)$ & $15(50)$ & \\
\hline \multicolumn{5}{|l|}{ WHO grade, $n(\%)$} \\
\hline 1 & $31(83.78)$ & $5(71.43)$ & $26(86.67)$ & \multirow[t]{3}{*}{0.57} \\
\hline II & $5(13.51)$ & $2(28.57)$ & $3(10)$ & \\
\hline III & $1(2.70)$ & $0(0)$ & $1(3.33)$ & \\
\hline \multicolumn{5}{|l|}{ Outcomes } \\
\hline In-hospital complications, n (\%) & $12(32.43)$ & $4(57.14)$ & $8(26.67)$ & 0.18 \\
\hline Stroke & $3(8.11)$ & $1(14.29)$ & $2(6.67)$ & 0.48 \\
\hline Seizure & $3(8.11)$ & $2(6.67)$ & $1(3.33)$ & 0.09 \\
\hline Other & $10(27.03)$ & $3(42.86)$ & $7(23.33)$ & 0.36 \\
\hline Length of stay, $\mathrm{d}$ & $7.76 \pm 8.70$ & $19.93 \pm 13.37$ & $4.93 \pm 3.59$ & $<0.001$ \\
\hline Nonroutine discharge, $n$ (\%) & $8(21.62)$ & $5(71.43)$ & $3(10)$ & $<0.001$ \\
\hline
\end{tabular}

Abbreviations: ASA, American Society of Anesthesiologists; WHO, World Health Organization.

Notel: Bold $\mathrm{p}$-value $=$ statistically significant.

complete hemostasis with the risk of inducing postoperative anemia and/or thrombocytopenia. Having said that, the removal of bone is a tenet of skull base surgery and can increase the risk of postoperative bleeding. Thus, meticulous hemostasis of cut bone is essential.
Cohen et al assessed the impact of RBC transfusion in cranial surgery through the National Surgical Quality Improvement Program database and demonstrated that compared with nontransfused patients, patients who received perioperative RBC transfusion had an increased risk of postoperative 
Table 2 Regression analyses

\begin{tabular}{|c|c|c|c|c|}
\hline & $\begin{array}{l}\text { Transfusion } \\
\text { (ref: no transfusion) }\end{array}$ & $\begin{array}{l}\text { In-hospital } \\
\text { complications }\end{array}$ & $\begin{array}{l}\text { Length of stay } \\
\text { (over } 14 \mathrm{~d} \text { ) }\end{array}$ & Nonroutine discharge \\
\hline Baseline & OR $[95 \% \mathrm{Cl}]$ & OR $[95 \% \mathrm{Cl}]$ & OR $[95 \% \mathrm{Cl}]$ & OR [95\% Cl] \\
\hline Age, $y$ & $1.11[1,1.24]$ & $1.03[0.96,1.09]$ & $1.03[0.92,1.19]$ & $1.07[0.98,1.16]$ \\
\hline Male (ref: female) & $0.76[0.62,0.93]$ & $0.63[0.11,3.73]$ & - & $0.45[0.04,4.31]$ \\
\hline Nonwhite (ref: white) & $7.85[0.84,17.04]$ & $1.52[0.38,6.09]$ & $4.53[0.46,45.16]$ & $1.79[0.36,8.90]$ \\
\hline \multicolumn{5}{|l|}{ Medical history (ref: no history) } \\
\hline Coagulopathy & $1.50[0.13,17.04]$ & $8.00[0.73,87.25]$ & $2.42[0.20,29.23]$ & $4.50[0.52,38.65]$ \\
\hline Antiplatelet & $0.39[0.04,3.71]$ & $2.86[0.63,12.92]$ & $0.64[0.06,6.52]$ & $1.89[0.36,9.97]$ \\
\hline Anticoagulant & $1.60[0.25,10.36]$ & $2.63[0.53,13.10]$ & $2.89[0.39,21.29]$ & $6.25[1.09,35.68]$ \\
\hline Stroke & $2.33[0.18,30.10]$ & $4.80[0.39,59.14]$ & $3.75[0.27,51.37]$ & $9.33[0.72,120.41]$ \\
\hline Seizure & $1.08[0.10,11.52]$ & $0.48[0.05,4.81]$ & - & - \\
\hline \multicolumn{5}{|l|}{ Hemoglobin } \\
\hline Preoperative & $0.68[0.42,1.08]$ & $0.98[0.67,1.43]$ & $0.93[0.43,2.00]$ & $0.79[0.51,1.22]$ \\
\hline Postoperative & $0.30[0.11,0.78]$ & $0.89[0.58,1.37]$ & $0.62[0.17,2.21]$ & $0.62[0.35,1.10]$ \\
\hline \multicolumn{5}{|l|}{ Platelet count } \\
\hline Preoperative & $1.00[0.99,1.01]$ & $1.00[0.99,1.01]$ & $1.00[0.99,1.01]$ & $1.00[0.99,1.01]$ \\
\hline Postoperative & $0.99[0.97,1.01]$ & $1.00[0.99,1.01]$ & $1.00[0.98,1.02]$ & 1.00 [0.99. 1.01] \\
\hline \multicolumn{5}{|l|}{ Meningioma } \\
\hline Skull base (ref: no) & $3.89[1.34,11.25]$ & $4.99[1.95,12.77]$ & $1.69[0.41,6.92]$ & $1.12[0.40,3.13]$ \\
\hline Vessel encasement (ref: no) & $4.32[0.71,26.13]$ & $2.49[0.61,10.18]$ & $6.67[0.66,66.84]$ & $5.70[0.97,33.60]$ \\
\hline Size, $\mathrm{cm}$ & $4.06[1.38,11.99]$ & $1.08[0.69,1.71]$ & $2.20[0.85,4.86]$ & $1.54[0.88,2.68]$ \\
\hline$>5 \mathrm{~cm}($ ref: $<5 \mathrm{~cm})$ & $75[5.80,970.66]$ & $1.43[0.11,18.30]$ & - & $6.25[0.38,102.71]$ \\
\hline ASA class III-IV (ref: I-II) & $3.47[0.37,32.74]$ & $0.94[0.22,4.07]$ & $2.10[0.21,21.10]$ & $4.28[0.46,39.60]$ \\
\hline \multicolumn{5}{|l|}{ Management } \\
\hline Embolization (ref: no) & $5.42[0.76,38.75]$ & $0.86[0.18,4.13]$ & $0.64[0.06,6.52]$ & $1.89[0.36,9.97]$ \\
\hline Operative time & $1.870[1.13,3.08]$ & $1.29[0.98,1.71]$ & $1.05[0.59,1.87]$ & $1.61[1.08,2.39]$ \\
\hline$>10$ h (ref: $<10$ h) & $12.50[1.87,83.60]$ & $5.25[1.11,24.91]$ & $5.35[0.74,38.64]$ & $8.00[1.42,44.92]$ \\
\hline Simpson grade (ref: I-III) & $2.35[0.40,13.80]$ & $2.17[0.52,9.09]$ & $4.00[0.40,39.83]$ & $1.56[0.31,7.75]$ \\
\hline Transfusion (ref: no transfusion) & - & $4.65[0.62,34.94]$ & $38.67[3.20,467.74]$ & $11.30[1.37,92.72]$ \\
\hline
\end{tabular}

Abbreviations: ASA, American Society of Anesthesiologists; Cl, confidence interval; OR, odds ratio; Ref, reference.

Table 3 Summary of the transfusion group

\begin{tabular}{|c|c|c|c|c|c|c|c|c|c|c|c|c|c|c|c|}
\hline Patient & Skull bas & menir & jioma & Manag & ment & & & & Trans & ision & & & Outcom & & \\
\hline Age/sex & Location & Size & Volume & Embo & Crani & Simpson & WHO & OT & Days & $\mathrm{Hb}$ & $\bar{U}$ & $\mathrm{~mL}^{\mathrm{a}}$ & Comp & LOS & Dispo \\
\hline $74 / \mathrm{F}$ & SW/PC & 6.5 & 120.4 & Yes & $\overline{\text { PT }}$ & IV & 1 & 11 & 0.25 & 8.6 & 2 & 620 & Other & 23.83 & SNF \\
\hline $65 / F$ & SW & 8 & 161.8 & No & PT & IV & II & 7 & 2.75 & 7.3 & 3 & 825 & Seizure & 46.36 & SNF \\
\hline $65 / F$ & PS & 5.2 & 34.75 & Yes & FR & IV & 1 & 12 & 1.19 & 8.4 & 1 & 275 & Stroke & 10.11 & Home \\
\hline $58 / \mathrm{F}$ & SW/PC & 5.1 & 34.7 & Yes & $\mathrm{FT}$ & II & I & 12 & 1.90 & 7.4 & 2 & 550 & None & 7.58 & ARU \\
\hline $60 / \mathrm{F}$ & SW & 5.4 & 67.32 & No & $\mathrm{FT}$ & IV & II & 9 & 3.99 & 7.3 & 2 & 550 & None & 17.84 & SNF \\
\hline $75 / \mathrm{F}$ & $\mathrm{PS} / \mathrm{OG}$ & 4 & 22.95 & No & FR & III & 1 & 11 & 4.21 & 7.6 & 2 & 550 & Seizure & 23.47 & SNF \\
\hline $74 / F$ & SW & 5.3 & 65.18 & Yes & PT & IV & 1 & 11 & 0.38 & 8.2 & 1 & 275 & None & 10.33 & Home \\
\hline
\end{tabular}

Abbreviations: Comp, in-hospital complications; Crani, craniotomy (approach); Days, days from surgery to transfusion; Dispo, discharge disposition; Embo, preoperative embolization; F, female; FR, frontal; FT, frontotemporal; Hb, pretransfusion hemoglobin value; LOS, length of stay; OG, olfactory groove; OT, operative time in hours (rounded up); PC, paraclinoid; PS, planum sphenoidale; PT, pterional; Size, maximal tumor diameter in centimeters; SW, sphenoid wing; Vol, tumor volume in millimeters; WHO, World Health Organization.

${ }^{a}$ One unit of packed red blood cells is defaulted to a volume of $275 \mathrm{~mL}$. 
complications, return to the operating room, prolonged hospital stays, and in-hospital mortality. ${ }^{15}$ In our study, the transfusion group was older and had larger tumors, longer operative times, longer hospital stays, and more nonroutine discharges than the no transfusion group. The United States Department of Health and Human Services Administration on Aging estimates that $\sim 28 \%$ of noninstitutionalized elderly persons live alone and this may influence discharge disposition. ${ }^{20}$

Importantly, larger meningiomas and longer procedures were risk factors for transfusion, but transfusion did not independently impact LOS or discharge disposition once we controlled for the effect of operative time. In fact, operative time greater than 10 hours was an independent risk factor for prolonged hospital stay once we controlled for the effect of transfusion. Thus, efforts should focus on safely reducing operative time.

\section{Limitations and Practice Recommendations}

There are several important limitations in addition to the retrospective study design. First, we focused on skull base meningiomas and this restricts the generalizability of our conclusions. To mitigate this, we retrieved data for all meningiomas resected at our institution during the same time period and provided comparisons when appropriate.

Second, there are likely other variables that affect the risk of transfusion that we did not measure in this study. For example, EBL is grossly underestimated, and thus, we chose not to evaluate it as a risk factor for transfusion. Our data suggested that more patients were successfully embolized in the transfusion group, but this did not reach statistical significance.

Third, our analysis was low-powered, which made it difficult to perform a subgroup analysis comparing transfusion strategies. In a previous study, Carson et al reviewed 31 randomized trials that compared transfusion strategies and reported that restrictive strategies resulted in no difference in in-hospital mortality, overall infection rate, functional recovery, LOS, or risk of myocardial infarction when compared with liberal transfusion strategies. ${ }^{21}$

In adult patients undergoing craniotomy for resection of skull base meningiomas, there remains insufficient data to advocate a specific transfusion strategy. Our recommendation is to transfuse at hemoglobin levels of 7 to $8 \mathrm{~g} / \mathrm{dL}$. However, in our study, 3/7 patients were transfused above that level. Thus, it is important to recognize the need to provide feedback and education to clinicians regarding RBC transfusion guidelines. ${ }^{22}$

\section{Conclusion}

In conclusion, we identified several risk factors for RBC transfusion following resection of skull base meningiomas: Those risk factors included skull base location, meningioma size greater than $5 \mathrm{~cm}$, and operative time greater than 10 hours. We discovered that the latter was an independent risk factor for prolonged hospital stay once we controlled for the effect of transfusion. However, transfusion alone cannot predict LOS or discharge disposition.

\section{Funding}

Carlito Lagman is supported by the Tina and Fred Segal Benign Brain Tumor \& Skull Base Surgery Research Fellowship. John P. Sheppard is supported by the David Geffen Medical Scholarship. Isaac Yang is partially supported by the UCLA Visionary Ball Fund Grant, Eli and Edythe Broad Center of Regenerative Medicine and Stem Cell Research UCLA Scholars in Translational Medicine Program Award, Jason Dessel Memorial Seed Grant, UCLA Honberger Endowment Brain Tumor Research Seed Grant, and Stop Cancer (US) Research Career Development Award.

\section{Acknowledgment}

None.

\section{References}

1 Carson JL, Guyatt G, Heddle NM, et al. Clinical practice guidelines from the AABB: red blood cell transfusion thresholds and storage. JAMA 2016;316(19):2025-2035

2 Alkhalid Y, Lagman C, Sheppard JP, et al. Restrictive transfusion threshold is safe in high-risk patients undergoing brain tumor surgery. Clin Neurol Neurosurg 2017;163:103-107

3 Practice guidelines for blood component therapy: a report by the American Society of Anesthesiologists Task Force on Blood Component Therapy. Anesthesiology 1996;84(03):732-747

4 Retter A, Wyncoll D, Pearse R, et al; British Committee for Standards in Haematology. Guidelines on the management of anaemia and red cell transfusion in adult critically ill patients. $\mathrm{Br} \mathrm{J}$ Haematol 2013;160(04):445-464

5 Napolitano LM, Kurek S, Luchette FA, et al; EAST Practice Management Workgroup; American College of Critical Care Medicine (ACCM) Taskforce of the Society of Critical Care Medicine (SCCM). Clinical practice guideline: red blood cell transfusion in adult trauma and critical care. J Trauma 2009; 67(06):1439-1442

6 Hamm CW, Bassand JP, Agewall S, et al; ESC Committee for Practice Guidelines. ESC Guidelines for the management of acute coronary syndromes in patients presenting without persistent ST-segment elevation: the Task Force for the management of acute coronary syndromes (ACS) in patients presenting without persistent ST-segment elevation of the European Society of Cardiology (ESC). Eur Heart J 2011;32(23):2999-3054

7 Ferraris VA, Ferraris SP, Saha SP, et al; Society of Thoracic Surgeons Blood Conservation Guideline Task Force; Society of Cardiovascular Anesthesiologists Special Task Force on Blood Transfusion. Perioperative blood transfusion and blood conservation in cardiac surgery: the Society of Thoracic Surgeons and The Society of Cardiovascular Anesthesiologists clinical practice guideline. Ann Thorac Surg 2007;83(5, Suppl):S27-S86

8 Qaseem A, Humphrey LL, Fitterman N, Starkey M, Shekelle P; Clinical Guidelines Committee of the American College of Physicians. Treatment of anemia in patients with heart disease: a clinical practice guideline from the American College of Physicians. Ann Intern Med 2013;159(11):770-779

9 Bagwe S, Chung LK, Lagman C, et al. Blood transfusion indications in neurosurgical patients: a systematic review. Clin Neurol Neurosurg 2017;155:83-89

10 Mantel N, Haenszel W. Statistical aspects of the analysis of data from retrospective studies of disease. J Natl Cancer Inst 1959;22 (04):719-748

11 Vassal O, Desgranges FP, Tosetti S, et al. Risk factors for intraoperative allogeneic blood transfusion during craniotomy for brain tumor removal in children. Paediatr Anaesth 2016;26 (02):199-206 
12 Mebel D, Akagami R, Flexman AM. Use of tranexamic acid is associated with reduced blood product transfusion in complex skull base neurosurgical procedures: a retrospective cohort study. Anesth Analg 2016;122(02):503-508

13 Awada WN, Mohmoued MF, Radwan TM, Hussien GZ, Elkady HW. Continuous and noninvasive hemoglobin monitoring reduces red blood cell transfusion during neurosurgery: a prospective cohort study. J Clin Monit Comput 2015;29(06):733-740

14 Kudo H, Fujita H, Hanada Y, Hayami H, Kondoh T, Kohmura E. Cytological and bacteriological studies of intraoperative autologous blood in neurosurgery. Surg Neurol 2004;62(03):195-199, discussion 199-200

15 Cohen JA, Alan N, Seicean A, Weil RJ. Risk associated with perioperative red blood cell transfusion in cranial surgery. Neurosurg Rev 2017;40(04):633-642

16 Pelargos PE, Nagasawa DT, Lagman C, et al. Utilizing virtual and augmented reality for educational and clinical enhancements in neurosurgery. J Clin Neurosci 2017;35:1-4
17 Cloutier JF, Bélair M, Saliba I. Superior semicircular canal dehiscence: positive predictive value of high-resolution CT scanning. Eur Arch Otorhinolaryngol 2008;265(12):1455-1460

18 Belden CJ, Weg N, Minor LB, Zinreich SJ. CT evaluation of bone dehiscence of the superior semicircular canal as a cause of soundand/or pressure-induced vertigo. Radiology 2003;226(02):337-343

19 Gaonkar B, Macyszyn L, Bilello M, et al. Automated tumor volumetry using computer-aided image segmentation. Acad Radiol 2015;22 (05):653-661

20 A Profile of Older Americans: 2014; 2017. Available at: https://aoa. acl.gov/aging_statistics/profile/2014/2.aspx. Accessed May 7, 2018

21 Carson JL, Stanworth SJ, Roubinian N, et al. Transfusion thresholds and other strategies for guiding allogeneic red blood cell transfusion. Cochrane Database Syst Rev 2016;10:CD002042

22 Carson JL, Grossman BJ, Kleinman S, et al; Clinical Transfusion Medicine Committee of the AABB. Red blood cell transfusion: a clinical practice guideline from the AABB*. Ann Intern Med 2012; 157(01):49-58 